\title{
Ties and inequalities in later life: welfare state regime and the role of social networks in health inequalities in later life in Europe
}

\author{
Daniela Craveiro
}

Communication and Society Research Centre, Universidade do Minho, Braga, Portugal

\begin{abstract}
Cross-national comparisons on health inequalities have puzzled health researchers in the last years. Contrary to what is theoretically expected, Northern European countries, known for their advanced welfare state regime and universalistic policies in health and social protection, do not present smaller health inequalities than other European nations. Within the debate triggered by these surprising results, some authors consider the possibility that the differences among the welfare state regimes may be shaping the relevance of specific pathways or mechanisms underlining the association between socioeconomic position (SEP) and health. This research addresses this hypothesis by comparing the contribution of social networks to health inequality in later life across different welfare state regimes. Mediation effects between SEP and health by social networks variables are compared across four different welfare state regimes, using data from Survey of Health, Ageing, and Retirement in Europe. Findings suggest that the socioeconomic advantages in health are partially explained by the differentials in social integration and quality of social ties. Welfare state regimes appear to shape the contribution of social networks in health inequality concerning the implications of the exchanges of social support in health.
\end{abstract}

ARTICLE HISTORY Received 12 March 2016; Accepted 10 October 2016

KEYWORDS Welfare state regime; health inequality; social networks

\section{Welfare state regime and health inequality}

Health inequality refers to the unjust and systematic differences in health that are related to differential access to material and social resources among individuals of different socioeconomic positions (SEPs) (Whitehead and Dahlgren 2007). Individuals of higher SEPs present better chances of good health than individuals of lower SEPs in populations all over the world. The Theory of Fundamental Causes provides a theoretical 
framework that accounts for the persistence of this association regardless of the evolution of specific health risks (Phelan et al. 2010; Freese and Lutfey 2011). Within theory, socioeconomic conditions are considered as fundamental causes of individual health. SEP is considered fundamental because it determines the access to the key resources that shape exposure and vulnerability to ill-health. Because socioeconomic resources can be used in multiple ways, they can ensure access to the better options available in a given society to cope with health risks. Therefore, the relative advantage in health of individuals of higher SEPs prevails throughout different times and contexts. This notion of flexible resources is quite crucial in theory. Under this premise health inequalities must be understood as contextualized relations, given the role of social contexts in shaping the relevance of the pathways and mechanisms that can translate socioeconomic differences into health inequalities.

The welfare state regimes have been pointed as a relevant contextual feature for health inequality. Welfare state regimes can be described as complex socio-politic compositions built through the times to regulate the relations between the state, the market and the individuals and their families. Multiple aspects of the social, economic, political and cultural contexts, which structure the life chances of individuals, are shaped by the type of the welfare state regime (Burstrom et al. 2010; Olasfsdottir \& Beckfield 2010). Welfare states' arrangements influence health by providing health-relevant goods and services that shape socioeconomic inequalities (Eikemo et al. 2008).

However, recent cross-national comparisons on health inequalities have been surprising researchers. The welfare states of Northern European nations are described by relatively lower levels of social stratification, and relatively higher levels of social protection, decommodification and defamiliarization. These features are expected to attenuate the effects of social stratification of the labour market, and the differences in exposure and vulnerability to negative health consequences across different SEPs (Diderichsen et al. 2001). Yet there is no systematic evidence that health inequality is smaller in the Northern European countries. Health inequalities studies reported (i) no differences on health inequalities (concerning income, education and occupational class differentials in mortality and morbidity) between Northern European countries and the countries from other regions or (ii) higher inequalities in Northern European countries than in the countries from other regions (Beckfield and Krieger 2009; Bambra 2011; Mackenbach 2012, for reviews). Figure 1 illustrates such a trend by comparing relative inequalities by level of education 


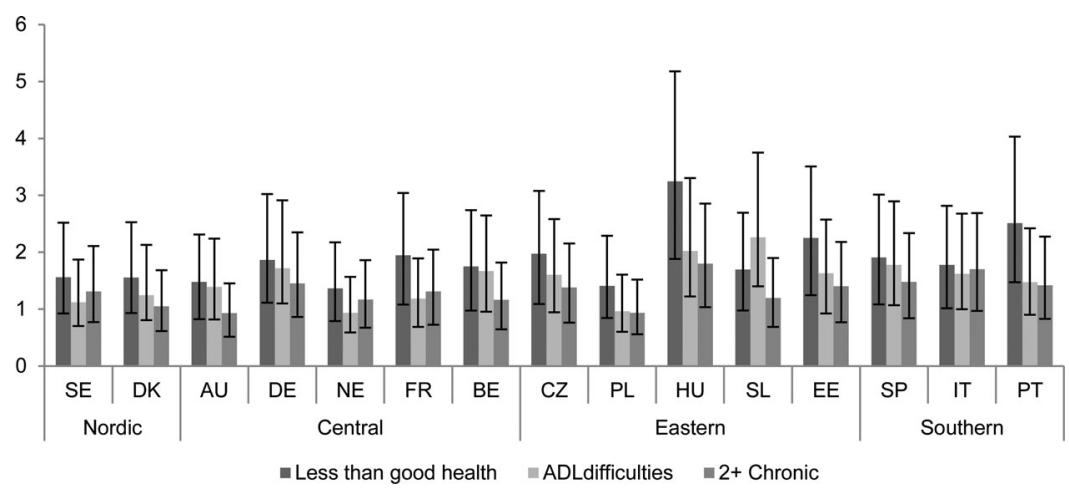

Figure 1. Morbidity odds ratio of lower education level individuals by country and European region (less than good health, ADL difficulties and more than two chronic conditions).

Notes: Less than good health: Fair or poor self-rated perception of health. ADL difficulties: Difficulties in ADL. 2+ Chronic: More than two chronic conditions. All indicators are self-reported. Bars represent relative odds ratio of individuals with less years of education than country median values compared to individuals with equal and above median values years of education. Lines represent the $95 \%$ confidence interval of the estimate. Models are adjusted by age and gender. Sweden (SE), Denmark (DK), Austria (AU), Germany $(\mathrm{DE})$, The Netherlands (NE), France (FR), Belgium (BE), Czech Republic (CZ), Poland (PL), Hungary (HU), Slovenia (SL), Estonia (EE), Spain (ES), Italy (IT), Portugal (PT). Source: SHARE w4 (2010), $N=53615$, unweighted data. Own calculations.

(above versus equal and above country median education years) across countries in three morbidity indicators. The graph shows how the relative educational disadvantage in health is not significantly lower in northern countries than the countries from other regions.

Within the debate triggered by these surprising results, some authors consider the possibility that the differences among the welfare state regimes may be shaping the relevance of specific pathways or mechanisms underlining the association between SEP and health (Mackenbach 2012). This study addresses this hypothesis by comparing the contribution of social networks to health inequality in later life across different welfare state regimes. Two main reasons support the focus. First, the extent to which people are forced to rely on their families and personal networks is among the key defying features that distinguish welfare state regimes (Arts and Gelissen 2002). Furthermore, personal social networks are the primal providers of social support, being crucial components of social security in old age (Kalmijn and Saraceno 2008).

This article is organized as follows. Firstly two additional sections are organized to further support the theoretical grounds of the research one dedicated to the discussion of theoretical links between social networks and health inequality, and another dedicated to welfare state 
regimes' differences in the assigned role of family and personal networks in the provision of support. Then, in the Method section, the selection of variables and analyses are presented and justified. This is followed by the presentation of the results, and a final section in which the findings are discussed, and systematized.

\section{Social networks and health inequality in later life}

Social networks can be conceptualized as a set of relevant social relationships established by an individual (Ferlander 2007). Social networks are a component of the individual social capital related to the potential and actual access to resources from their social connections (van Oorschot and Finsveen 2009). Among these relationships, it is possible to enumerate 'strong' and 'weak' ties, distinguishing relationships of close significant others from relationships with similar others, such as neighbours or acquaintances (Granovetter 1973). The present study focuses on the characteristics and implications of close relationships (personal social networks) given their particular relevance in old age (Waite and Das 2010).

Social relations can influence what we do (by social influence, social control or social comparison processes), how we feel (by influencing our self-esteem, sense of control and sense of belonging) or the help we can get to cope with life events (social support), which have direct and indirect implications on our health and well-being (Berkman et al. 2000; Thoits 2011). Social networks that are bigger, more diverse, more social integrated and more reliant on close ties are associated with better health and well-being in later life (e.g. Litwin 1998; Fiori et al. 2006; Pirani and Salvini 2011). The simplicity of such a relation is disputed, though. It is acknowledged that not all social ties are equally supportive, and that relationships can be a source of conflict and demands with negative feedback on health (Smith and Christakis 2008).

Agreeing with the Theory of Fundamental Causes, the social economic position of an individual relates to access to resources that can be used in health-relevant ways, and part of these resources can be accessed throughout social contexts and social connections. Higher SEPs are associated with advantages in personal social networks, in terms of availability of social resources (material, cultural, symbolic), which may contribute to ensuring better health chances (Phelan et al. 2010).

DiMaggio and Garip (2012), based on a literature review from multiple fields, identified different ways how social network could reinforce social inequality, naming three main mechanisms: local network externalities 
(related with the characteristics shared among the 'weak' ties, such as communities), social learning and peer assistance, and normative influence. According to the authors the contribution of networks in inequality should be particularly important in the situations when people make decisions. Take the example of smoking, a behaviour that contributes to enhancing health inequalities. Lower socioeconomic individuals may increase the chances of starting to smoke given the higher prevalence of smokers in the poorer neighbourhoods (network externalities), the exposure to people smoking (social learning) or the group-shared beliefs on tobacco hazards (normative influence of the group). Social inequality is also re-enforced when network effects enhance the health of people of higher SEPs (e.g. the decision of doing exercise regularly can be promoted by the existence of better parks and infrastructures of richer neighbourhoods, by the example of others or the social valorization of physical activity among the social network). Additionally, social network can work as a personal security system to buffering the impact of adversities (such as losing a job or getting sick). Due to our tendency to relate with people that share similar social traits, such as social class, even considering the role of informal social supprt, that is non-financially ensured, it is expected that the social ties of individuals from higher SEPs have better conditions and resources to provide social support in the form of either emotional sustenance or active coping assistance (DiMaggio and Garip 2012; Thoits 2011).

In this regard, the contributions of Bourdieu's works in uncovering the mechanisms related to the social reproduction of inequality are also relevant (Uphoff et al. 2013; Abel et al. 2011). Bourdieu's understandings of social distinction relied on the dynamic interaction among economic, social (social networks included) and cultural capitals. Different social classes present specific configurations of the relation of these capitals, and the social advantage in a particular field would rely on the activation and interaction of all types of capitals. Higher SEPs are correlated to advantages in multiple dimensions of social life (material, behavioural, cultural, social), including the resources associated with personal social networks. People of higher SEPs tend to have more resources and opportunities to benefit from their personal networks (Bourdieu 1984; Abel 2008).

The relation between socioeconomic position and health is expected to be partially explained by differentials in social networks resources. In this line of reasoning, social networks are conceived as mediators between SEP and health. 
Among the few studies that address the contribution of social networks to health inequality, there are some authors that report relevant mediation effects of social networks characteristics in the association between SEP and health, concerning self-rated health among French adults (Heritage 2009), depression among Dutch and Finnish older adults (Koster et al. 2006; Huurre et al. 2007), stroke in Northern Americans older adults (Avendano et al. 2006) or even social inequalities in mortality among older Taiwanese (Liu et al. 1998). Income, education and occupational differentials in health are partially explained by social networks characteristics, such as composition (size, partner), strength of ties, social support or social participation - these studies show how higher socioeconomic status is associated with bigger networks, higher chances of having a partner, emotionally closer ties, higher perceptions of social support and more frequent social participation, which contribute to partially explain health advantages of higher-class individuals. However, other studies suggest that social networks features do not contribute to mediating the association between SEP and health (e.g. Chappell and Funk 2010; Dahl and Malmberg-Heimonen 2010). Besides the contradicting results, none of these studies addressed the implications of the macro-institutional setting in the role of social networks in health inequalities, or the specificities of the older population.

\section{Social networks and welfare state regimes in Europe}

In this study countries were grouped according to different welfare state regimes, according to Ferrera's (1996) proposal. This author presented a welfare state regime typology within the debate on welfare modelling triggered by the seminal proposal of Esping-Anderson in which three worlds of welfare were identified $(1990,1999)$. One of the most consistent criticisms of the Esping-Anderson's typology concerned the misspecification of the role of the family (or personal social networks) in the provision of welfare. This issue led to the introduction of the concept of defamiliarization that considers the level of independence from familial relationships to individuals achieving a reasonable standard of living. The added dimension came to underline the importance of considering the type of support alongside the amount of support provided by the state in the differentiation of welfare state regimes (Bonoli 1997). Ferrera (1996) accounts for these dimensions by attending to differences in the rules of access of social security systems, the conditions of access to social benefits, the regulations in financing social protection and the organizational arrangements 
of different security schemes (Ferrera 1996). According to these criteria, European countries were sorted into four groups: Scandinavian, AngloSaxon, Bismarckian and Southern states.

In Scandinavian countries social security systems provide universal coverage accessed on the basis of citizenship rights, which are financed through fiscal revenues, and described by strong organizational integration between different systems. In Anglo-Saxon countries social assistance tends to be delivered by means-tested benefits, being financed by public and private funds, in a system strongly integrated and managed by a public administration. In Bismarckian countries social entitlements are strongly linked to the work position, and social protection schemes are financed by income-related contributions and mainly governed by unions and employers. Finally, in Southern European countries social protection is delivered by a fragmented system composed of several income schemes with different levels of social protection, ensuring just health care as a right of citizenship. Southern countries also differ from other clusters due to a stronger reliance on the family and charitable sectors (Ferrera 1996).

Although there is no consensus in the literature regarding the specificity of this fourth cluster, this typology allows addressing the cross-national variability on the arrangements in the availability of social services and different commitments to familiarization and defamilialization pressures - a crucial point when attending to the role of social networks in health and well-being. Also, other authors have pointed out important differences in the formalization of care provision by the state across different welfare state regimes very much in line with Ferrera's approach (e.g. Anttonen and Sipilä 1996; Leitner 2003). ${ }^{1}$

These differences in the provision of support by the state influence the degree of dependence of individuals in their personal networks. Welfare state regimes are, therefore, related to the composition of households, intergenerational relations, personal social networks and amounts of social support provided and received (e.g. Scheepers et al. 2002; Leitner 2003; Litwin 2009; Gelissen et al. 2012; Litwin and Stoeckel 2014; García-Faroldi 2015). Nations with less defamiliarized regimes are described by higher levels of intergenerational co-residence and contacts

\footnotetext{
${ }^{1}$ Anttonen and Sipilä (1996) identified different configurations of formal and informal support availability in Scandinavian, Anglo-Saxon, Western European and Mediterranean countries. Leitner (2003) proposed a framework to account for the several modalities in the family role (familialism) in the provision of care, which allows to distinguish the care regimes from countries from the north (optional), centre (explicit) and south of Europe (implicit).
} 
(Leitner 2003; Kääriäinen and Lehtonen 2006), family-dominant social networks types (Litwin 2009; Litwin and Stoeckel 2014) and higher reliance on family ties to social support (Kalmijn and Saraceno 2008; García-Faroldi 2015). Besides those differences, empirical studies suggest that the defamiliarization and comprehensiveness of welfare states do not erode the importance of social networks in health and well-being (crowd out hypothesis), existing more empirical support for the opposite association (crowd in hypothesis) (Kääriäinen and Lehtonen 2006; Gelissen et al. 2012).

This study aims to study the role of the characteristics of social networks in the mediation of the association between SEP and health, among aged populations living in different macro-institutional settings. Considering the differences among the welfare state regimes, the influence of social support provided by social networks is expected to change across regions. The provision of social support should be more relevant for health inequalities in the Southern and the Eastern regions than in the Scandinavian and Bismarckian states, where there is higher social support provision by the state.

\section{Method}

\subsection{Data and sample}

This research relies on data from the Survey of Health, Ageing and Retirement in Europe (SHARE). SHARE consists of a multidisciplinary and cross-national panel database of micro-data on health, socioeconomic status, and social and family networks. It ensembles representative samples of non-institutionalized populations aged 50 and above from 20 European countries (+Israel) (see Börsch-Supan et al. 2013, for sampling and other methodological details). Data used in this study concern the data from the fourth wave of the survey, collected between 2010 and 2011, which compiled the most recent data available on Social Networks. The sample is composed of 53,615 individuals, aged between 50 and 111 years old $(M=66.31 ; \mathrm{SD}=10.04)$, from 15 European countries (Austria, Belgium, Czech Republic, Denmark, Estonia, France, Germany, Hungary, Italy, The Netherlands, Poland, Portugal, Slovenia, Spain and Sweden). ${ }^{2}$ Countries were grouped according to an adaptation of Ferrera's (1996) welfare typology that includes the consideration of the additional

\footnotetext{
${ }^{2}$ Data from Switzerland were also available in the survey, but they are omitted from this research due to the difficulty of classifying the welfare state regime of the country with the typology adopted.
} 
cluster of Eastern European countries and the omission of the AngloSaxon regime due to data availability issues - Scandinavian $(N=4170)$, Bismarckian states $(N=20,270)$, Eastern $(N=20,126)$ and Southern $(N=9049)$.

\subsection{Main variables}

\subsubsection{Socioeconomic position}

SEP refers to the place of an individual in a hierarchy based on socioeconomic characteristics, expressed in the distinctive access of resources and valued goods. In the present study, variables defining education, income, perceived income adequacy and wealth were selected to account for socioeconomic differences. The education level was measured by the years in which participants were enrolled in full-time formal education. Income was measured by considering the sum of the income components of the individual and the household (wages, pensions, benefits and others). The wealth variable was calculated as the sum of all financial and real assets minus liabilities. The variables Income and Wealth were adjusted for household size (divided by the squared root of household size) and divided in quintiles in each country sample. Perceived income adequacy was defined based on a subjective measure of income availability (Is the household able to make ends meet?), considering the four levels of response. The four variables were combined in order to generate the SEP factor, computed through the application of a Factor Analysis (Principal Component Analysis). The procedure was conducted in each country separately to allow different configurations of the importance of the components of the factor, in order to have for a more country-specific measure. The computed factor was used as the SEP variable (regression method), wherein higher values mean higher social standings.

\subsubsection{Social networks}

Based upon the consulted literature on social network types among older adults (e.g. Fiori et al. 2006; Litwin 2009), eight indicators were selected to assess the three key features of social networks in later life - the structure of the social network, the quality of the ties and the exchanges in terms of social support (Fiori et al. 2006). The structural characteristics of the social network were described with four variables, namely: Size (number of members in the personal network) and Social participation (participation in social activities in the 12 months prior to the interview). The quality of ties was assessed by the level of overall satisfaction of the social relations 
considered in the network (measured in a 10-point scale); the existence of daily contact with at least one member of the social network (Daily contact) and the existence of at least one relation in the network considered extremely close (Emotional closeness). Finally, the social support exchanges were considered by four variables, considering if there were exchanges (received and provided) in the 12 months prior to the data collection, in terms of financial help, and the provision of instrumental help (help with personal care or household chores, from inside or outside the household).

\subsubsection{Health}

Health was measured considering an aggregated variable defined based on the account of three variables selected to account for the three dimensions most mentioned in the studies on health conceptions - subjective, functional and biomedical dimensions of health (Hughner and Kleine 2004). The variables self-perception of health (rated in a five-point scale, wherein higher values mean worse health perceptions), number of difficulties in activities of daily living (ADL) and number of chronic conditions were combined in a Factor Analysis (Principal Component Analysis). The retention of the first component generated the Health factor, wherein higher values mean worse health. Some argue that the integration of a subjective component may limit the comparability of the variable across nations (e.g. Quesnel-Valleé 2007). The possible bias is minimized in the study by the aggregation of countries with similar cultural features (expressed by policy and geographic affinities) and the addition of country dummy variables in the regression models.

\subsubsection{Welfare state regime}

Countries were grouped into four clusters (Scandinavian, Bismarckian, Eastern, Southern) according to different welfare state regime features, taking as reference Ferrera's typology (1996). Two adaptations were made to the original typology. The first is the omission of Anglo-Saxon countries that do not figure in the database. The second adaptation refers to the addition of the Eastern European cluster. Eastern European countries were not considered in Ferrera's typology, given their very recent configuration. Considering similarities and specificities driven by a common political past, countries from the former socialist block have been considered as a different type of welfare regime. Eastern European countries assisted in the replacement of a full universal coverage flatrate system by one that emphasizes insurance-based and contribution- 
based benefits, and the introduction of systems of minimum income protection, similar in design to ones in Central Europe (Aspalter et al. 2009; Requena 2010). The integration of Eastern countries in welfare state studies has also been reflected in the increased use of five European welfare regimes in public health research (e.g. Eikemo and Bambra 2008; Requena 2010) - ensuring the comparability of the research with other studies on the topic.

\subsection{Analysis}

The mediation effects of each one of the social networks variables were estimated based on the product coefficient approach (MacKinnon et al. 2002). The coefficients of the mediation effects were calculated as the product of the regression coefficients between (i) the SEP factor and (each one of) the social networks characteristics (path a) (ii) and between the social networks characteristics of the Health factor, controlling for the SEP factor (path b). A Sobel test was applied to each mediation relation under study, providing an estimation for the standard error of the calculated mediation effect, assessing their statistical significance (Sobel 1982). In all models age, gender and country are included as covariates. For the cases of dichotomous mediators the coefficients were made comparable across the equations (path a and path b) in accordance with MacKinnon and Dwyer (1993).

The results obtained were compared across regions by pair-wise comparisons of the estimated mediation coefficients, and the statistical significance of the differences between regional areas assessed by the calculation of a $z$-test statistic. Analyses were made with the support of the SPSS.20 statistical software and the Excel application from Microsoft Office 2011.

\section{Results}

The participants had an average age of around 66 years, and there were higher percentages of women than of men, in all regions. Participants tended to report two to three members in their personal networks in all regions, but the size of the social network was higher in the Scandinavian and Bismarckian states. Daily contact was very frequent, especially in the Southern states, and participants presented high levels of satisfaction. Sensibly half of the samples from Eastern Europe and almost three-quarters of the samples from the Scandinavian (66.9\%), the Bismarckian (70\%) and Southern $(69.1 \%)$ states reported having at least one (extremely) close 
emotional tie. More people provided social support than they received. The highest percentages of providing (financial and instrumental) help were showed in the Scandinavian sample (39.3\% and 37.0\%, respectively). A similar trend is found in the variable Receiving financial support (particularly low in Southern European states) (Table 1).

The indirect effects of each one of the social networks variables were assessed by the product of the coefficient approach. The regression coefficients related to paths (a) and (b), the estimation for the mediation effect coefficient and the respective Sobel test statistics are presented for each network variable in Table 2.

In the Scandinavian sample, the Sobel tests allowed the identification of mediation effects, between the SEP factor and the Health factor, through the variables Social participation and Satisfaction $(p<.05)$. SEP influences the chances of participating in social activities and the chances of perceiving higher levels of satisfaction which, in turn, are related to better health status (lower Health factor scores). This implies that part of the health advantages (lower Health factor scores) that are associated with higher SEPs can be attributed to higher social integration levels (social participation and satisfaction level) related to those social standings.

Among the Bismarckian states, the mediation effects through the variables Social participation and network Satisfaction are shown to be statistically different from zero and negatively associated with the Health factor. The association of the SEP factor with the Health factor in this cluster is also mediated by the exchanges of social support - Providing financial help, Providing instrumental help, Receiving financial help and Daily contact. In these cases, however, the estimated coefficients are positive, that is, the mediation effects are associated with higher scores in the Health factor. The exchanges of social support are related to worse health status (higher scores in the Health factor). Since those exchanges increase with the increase of the social economic position, the exchange of social support attenuates health inequalities, decreasing the association between higher SEPs and better health (lower health scores). Within the Fundamental Causes Theory the mechanisms linking SEP and health are expected to change. Still these results reveal an additional complexity on the contribution of social networks to health inequality by exposing an association that undermines mainly higher class individuals. Therefore, these associations cannot be conceived as a mechanism to inequality in these states but appear to be signalling some sort of confounding effect that may be contributing to the unexpected findings in recent crossnational comparisons that were referred to in the beginning of the paper. 
Table 1. Descriptive statistics by sub-sample.

\begin{tabular}{|c|c|c|c|c|c|c|c|c|}
\hline & Scar & vian & Bis & kian & & & & \\
\hline & $\begin{array}{c}N \\
(M)\end{array}$ & $\begin{array}{c}\% \\
\text { (SD) }\end{array}$ & $\begin{array}{c}N \\
(M)\end{array}$ & $\begin{array}{c}\% \\
\text { (SD) }\end{array}$ & $\begin{array}{c}N \\
(M)\end{array}$ & $\begin{array}{c}\% \\
\text { (SD) }\end{array}$ & $\begin{array}{c}N \\
(M)\end{array}$ & $\begin{array}{c}\% \\
\text { (SD) }\end{array}$ \\
\hline Age & (66.49) & $(10.2)$ & (66.14) & $(10.25)$ & $(66.08)$ & $(9.72)$ & (67.06) & (10.13) \\
\hline Female & 2247 & 53.9 & 11294 & 55.7 & 11583 & 57.6 & 4958 & 54.8 \\
\hline Male & 1923 & 46.1 & 8976 & 44.3 & 8543 & 42.4 & 4091 & 45.2 \\
\hline Socioeconomic in & & & & & & & & \\
\hline Education years & $(10.4)$ & $(5.2)$ & $(10.9)$ & (4.4) & $(11.2)$ & (3.4) & (7.4) & $(4.7)$ \\
\hline Income $(€)$ & $(32,156.54)$ & $(19,969.95)$ & $(29,937.89)$ & $(38,648.91)$ & (8052.93) & $(12,244.03)$ & $(14,786.53)$ & $(31,058.41)$ \\
\hline Wealth $(€)$ & $(253,664.78)$ & $(328,140.79)$ & $(206,473.94)$ & $(316,227.77)$ & $(64,660.32)$ & $(447,090.24)$ & $(160,022.64)$ & $(277,211.59)$ \\
\hline Ends are met wit & & & & & & & & \\
\hline Great difficulty & 82 & 1.3 & 1212 & 18.8 & 3420 & 53.0 & 1742 & 27.0 \\
\hline Some difficulty & 429 & 2.7 & 3967 & 24.8 & 8287 & 51.8 & 3316 & 20.7 \\
\hline Fairly easily & 1227 & 7.0 & 7649 & 43.4 & 5899 & 33.5 & 2854 & 16.2 \\
\hline Easily & 2383 & 18.1 & 7228 & 54.8 & 2450 & 18.6 & 1119 & 8.5 \\
\hline Health variables & & & & & & & & \\
\hline Chronic diseases & (1.45) & (1.36) & $(1.68)$ & $(1.52)$ & $(1.95)$ & $(1.62)$ & $(1.84)$ & $(1.58)$ \\
\hline ADL limitations & $(0.19)$ & $(0.76)$ & $(0.24)$ & $(0.82)$ & $(0.29)$ & $(0.91)$ & $(0.37)$ & (1.13) \\
\hline Self-perceived he & & & & & & & & \\
\hline Excellent & 749 & 22.5 & 1600 & 48.1 & 546 & 16.4 & 428 & 12.9 \\
\hline Very good & 1226 & 15.1 & 3824 & 47.1 & 1930 & 23.8 & 1138 & 14.0 \\
\hline Good & 1078 & 5.8 & 8089 & 43.7 & 6246 & 33.7 & 3094 & 16.7 \\
\hline Fair & 831 & 5.1 & 5079 & 30.9 & 7533 & 45.8 & 2992 & 18.2 \\
\hline Poor & 286 & 4.0 & 1678 & 23.2 & 3871 & 53.5 & 1397 & 19.3 \\
\hline
\end{tabular}

(Continued) 
Table 1. Continued.

\begin{tabular}{|c|c|c|c|c|c|c|c|c|}
\hline & \multicolumn{2}{|c|}{ Scandinavian } & \multicolumn{2}{|c|}{ Bismarckian } & \multicolumn{2}{|c|}{ Eastern } & \multicolumn{2}{|c|}{ Southern } \\
\hline & $\begin{array}{c}N \\
(M)\end{array}$ & $\begin{array}{c}\% \\
\text { (SD) }\end{array}$ & $\begin{array}{c}N \\
(M)\end{array}$ & $\begin{array}{c}\% \\
\text { (SD) }\end{array}$ & $\begin{array}{c}N \\
(M)\end{array}$ & $\begin{array}{c}\% \\
\text { (SD) }\end{array}$ & $\begin{array}{c}N \\
(M)\end{array}$ & $\begin{array}{c}\% \\
\text { (SD) }\end{array}$ \\
\hline \multicolumn{9}{|l|}{ Social networks variables } \\
\hline Daily contact & 3406 & 81.7 & 16017 & 79.0 & 17477 & 86.8 & 8398 & 92.8 \\
\hline Emotional closeness & 2791 & 66.9 & 14181 & 70.0 & 10561 & 52.5 & 6257 & 69.1 \\
\hline Satisfaction & $(9.2)$ & $(1.3)$ & (8.76) & (1.36) & (8.85) & (1.59) & (8.92) & $(1.44)$ \\
\hline Total & 4170 & 100 & 20270 & 100 & 20126 & 100 & 9049 & 100 \\
\hline
\end{tabular}

Note: $N$ (frequency), \% (percentage), $M$ (mean), SD (standard deviation). Income and wealth values adjusted for the square root of the size of household (members). 
Table 2. Mediation coefficients' estimates for each social network feature.

\begin{tabular}{|c|c|c|c|c|c|c|c|}
\hline \multirow[b]{3}{*}{ Region } & \multirow[b]{3}{*}{ Social network } & \multirow{2}{*}{\multicolumn{2}{|c|}{$\begin{array}{l}\text { Path (a) } \\
\text { Factor SES - } \\
\text { ocial network }\end{array}$}} & \multirow{2}{*}{\multicolumn{2}{|c|}{$\begin{array}{c}\text { Path }(b) \\
\text { ocial network - } \\
\text { health factor }\end{array}$}} & \multirow{2}{*}{\multicolumn{2}{|c|}{$\begin{array}{l}\text { Mediation effect } \\
\text { (social network) }\end{array}$}} \\
\hline & & & & & & & \\
\hline & & $B$ & SE & $B$ & SE & $B$ & SE \\
\hline \multirow[t]{8}{*}{ Scandinavian } & Size & $.191^{* * *}$ & .019 & .002 & .006 & -.001 & .001 \\
\hline & Social participation & $.435^{* * *}$ & .026 & $-.185^{* * *}$ & .019 & $-.012^{* * *}$ & .002 \\
\hline & Daily contact & $.368^{* * *}$ & .031 & .009 & .023 & .002 & .002 \\
\hline & Emotional closeness & $.170^{* * *}$ & .025 & -.034 & .019 & -.002 & .001 \\
\hline & Satisfaction & $.097^{* * *}$ & .015 & $-.045^{* * *}$ & .007 & $-.015^{* *}$ & .005 \\
\hline & Provided financial help & $.66^{* * *}$ & .027 & .027 & .019 & .002 & .003 \\
\hline & Provided instrumental help & $.149 * * *$ & .025 & .014 & .019 & .000 & .001 \\
\hline & Received financial help & $.246^{* * *}$ & .032 & .024 & .024 & .000 & .001 \\
\hline \multirow[t]{8}{*}{ Bismarckian } & Size & $.254^{* * *}$ & .012 & .002 & .004 & .000 & .001 \\
\hline & Social participation & $.463^{* * *}$ & .015 & $-.173^{* * *}$ & .013 & $-.012^{* * *}$ & .001 \\
\hline & Daily contact & $.182^{* * *}$ & .018 & $.051^{* * *}$ & .015 & $.001^{* *}$ & .000 \\
\hline & Emotional closeness & $.176^{* * *}$ & .017 & .006 & .014 & -.012 & .001 \\
\hline & Satisfaction & $.044^{* * *}$ & .01 & $-.029 * * *$ & .005 & $-.078^{* * *}$ & .006 \\
\hline & Provided financial help & $.673^{* * *}$ & .017 & $.056^{* * *}$ & .013 & $.005^{* * *}$ & .001 \\
\hline & Provided instrumental help & $.157^{* * *}$ & .016 & $.048^{* * *}$ & .013 & $.001^{*}$ & .000 \\
\hline & Received financial help & $.354^{* * *}$ & .02 & $.034^{*}$ & .016 & $.001^{* * *}$ & .001 \\
\hline \multirow[t]{8}{*}{ Eastern } & Size & $.232^{* * *}$ & .01 & $.031^{* * *}$ & .005 & $.006^{* * *}$ & .001 \\
\hline & Social participation & $.475^{* * *}$ & .016 & $-.171^{* * *}$ & .014 & $-.011^{* * *}$ & .001 \\
\hline & Daily contact & $.269 * * *$ & .023 & $.086^{* * *}$ & .019 & $.002^{* * *}$ & .001 \\
\hline & Emotional closeness & $.173^{* * *}$ & .016 & .01 & .014 & .000 & .000 \\
\hline & Satisfaction & $.165^{* * *}$ & .011 & $-.009^{*}$ & .004 & $-.080^{*}$ & .007 \\
\hline & Provided financial help & $.573^{* * *}$ & .017 & $.044^{* * *}$ & .014 & $.003^{* *}$ & .001 \\
\hline & Provided instrumental help & $.18^{* * *}$ & .016 & $.108^{* * *}$ & .014 & $.003^{* * *}$ & .000 \\
\hline & Received financial help & $.335^{* * *}$ & .021 & $.05^{* *}$ & .018 & $.002^{* * *}$ & .001 \\
\hline \multirow[t]{8}{*}{ Southern } & Size & $.217^{* * *}$ & .017 & -.005 & .006 & -.001 & .001 \\
\hline & Social participation & $.453^{* * *}$ & .024 & $-.106^{* * *}$ & .022 & $-.006^{* * *}$ & .001 \\
\hline & Daily contact & $-.072^{* * *}$ & .042 & $.097^{*}$ & .038 & -.001 & .000 \\
\hline & Emotional closeness & $.059 * * *$ & .023 & $.048^{*}$ & .021 & .000 & .000 \\
\hline & Satisfaction & $.055^{* * *}$ & .015 & -.003 & .007 & -.049 & .010 \\
\hline & Provided financial help & $.608^{* * *}$ & .028 & .096 & .025 & $.007^{* * *}$ & .002 \\
\hline & Provided instrumental help & $.166^{* * *}$ & .025 & $.180^{* * *}$ & .023 & .004 & .001 \\
\hline & Received financial help & $.388^{* * *}$ & .037 & .066 & .035 & $.002^{* * *}$ & .001 \\
\hline
\end{tabular}

Notes: Regression coefficients $(B)$ and related standard error (SE). Mediation coefficients estimation based on coefficients presented in the comparable format agreeing with the proposal of MacKinnon and Dwyer (1993), statistical significance based on the Sobel test statistic.

${ }^{*} p<.05$.

${ }^{* *} p<.01$.

${ }^{* * *} p<.001$.

Positive and negative mediation coefficients are also identified in the Eastern and in the Southern European regions. In the Eastern Europe sample, the variables Social participation and Satisfaction presented relevant mediation effects that are related to the decrease of the Health factor scores. In turn, the variables Size, Daily contact, Providing financial, Providing instrumental help and Receiving financial help present statistically significant mediation effects in relation to the increase of the Health factor.

In the Southern European sample, again, the mediation effect of the variable Social participation presented a negative coefficient, suggesting 
a role of social participation in explaining the health advantages of higher SEPs. The mediation effects related to the exchanges of financial help also were shown as statistically relevant, although presenting positive coefficients.

The mediation coefficients were compared across regions by pair-wise comparisons supported by $z$-test statistics (Table 3).

Regions differed in the mediation coefficients considered statistically relevant, indicating regional differences in the pathways to health inequality and stronger empirical evidence for the notion of flexible resources introduced by the Theory of Fundamental Causes.

The Southern European states presented the lowest mediation coefficient (in absolute terms) related to the Social Participation variable, being statistically significantly lower than in any other region $(p<.05)$. The mediation effects related to the variable Satisfaction only differed among regions when compared with the Southern Europe sample, where the coefficient is so low that it is not statistically different from zero considering a 95\% confidence level. Regional differences in social support are also validated by the pair-wise comparisons. The mediation effects of the variable provision of instrumental support are bigger in Southern region than the ones calculated in the other regions, with the exception of the Eastern region $(p<.05)$. These are particularly interesting differences as they relate to the unexpected associations and because they differ by regimes with higher (Eastern and Southern countries) and lower dependencies (Scandinavian and Bismarckian) on personal social networks for the provision of care and support.

\section{Discussion and conclusion}

The role of social networks in health inequality was studied by assessing the contribution of social networks variables in the association between the SEP factor and the Health factor. The findings suggest that social networks contribute to mediate socioeconomic differences in health and that the role of social exchanges differ across welfare regions.

Socioeconomic differences in health are partially explained by the social differences in social participation and network satisfaction and relevance of these pathways varied across regimes.

Furthermore, an unexpected mediation relation was identified in all regions except in the Northern region. The social network features related with social support, because more prevalent in individuals of higher SEP, attenuate health inequalities by negatively impacting health. 
Table 3. Pair-wise comparisons of mediation coefficients' estimates across regimes (z-test statistic).

\begin{tabular}{|c|c|c|c|c|c|c|}
\hline Social network & $\begin{array}{l}\text { Scandinavian vs. } \\
\text { Bismarckian }\end{array}$ & $\begin{array}{l}\text { Scandinavian vs. } \\
\text { Eastern }\end{array}$ & $\begin{array}{l}\text { Scandinavian vs. } \\
\text { Southern }\end{array}$ & $\begin{array}{l}\text { Bismarckian vs. } \\
\text { Eastern }\end{array}$ & $\begin{array}{l}\text { Bismarckian vs. } \\
\text { Southern }\end{array}$ & $\begin{array}{l}\text { Eastern vs. } \\
\text { Southern }\end{array}$ \\
\hline Size & -0.707 & $-4.061^{* * *}$ & -0.121 & $-4.029^{* * *}$ & 0.619 & $4.208^{* * *}$ \\
\hline Social participation & -0.113 & -0.250 & $-2.285^{*}$ & -0.217 & $-3.060^{* *}$ & $-2.844^{* *}$ \\
\hline Daily contact & 0.192 & -0.375 & 0.988 & -1.847 & $3.217^{* *}$ & $4.324^{* * *}$ \\
\hline Emotional closeness & $7.712^{* * *}$ & -1.930 & $-2.150^{*}$ & $-11.869^{* * *}$ & $-12.446^{* * *}$ & -0.313 \\
\hline Satisfaction & $7.798^{* * *}$ & $7.567^{* * *}$ & $2.970^{* *}$ & 0.175 & $-2.448^{*}$ & $-2.517^{*}$ \\
\hline Provided financial help & -1.115 & -0.528 & -1.611 & 1.114 & -0.900 & -1.776 \\
\hline $\begin{array}{l}\text { Provided instrumental } \\
\text { help }\end{array}$ & -1.114 & $-3.378^{* * *}$ & $-3.782^{* * *}$ & $-3.034^{* *}$ & $-3.420^{* * *}$ & -1.427 \\
\hline Received financial help & -1.818 & $-2.267^{* *}$ & -1.840 & -0.387 & -0.608 & -0.344 \\
\hline
\end{tabular}

${ }^{*} p<.05$.

${ }^{* *} p<.01$.

${ }^{* * *} p<.001$. 
The relation was not expected in the scope of the hypothesis drawn for this research but it highlights the predicted differences across welfare regions. These associations are reported in the Birsmarckian, Eastern and Southern Europe states concerning the provision of social support.

In agreement with the theoretical framework, the findings suggest that in regions where there is a higher dependency on personal social networks for the provision of care and support, the advantage of higher SEPs in health decreases due to the provision of social support. Exchanges of support can imply a higher depletion of personal resources in these settings, than in more defamiliarized states like the ones in Northern Europe. The absence of universal policies in care and social support services can constrain the health chances of older adults of higher SEPs, in a process that may be 'artificially' decreasing the socioeconomic implications in health. Social support provision appears to not be a relevant pathway to health inequality in these regimes (since it reports health disadvantages for both higher and lower socioeconomic individuals). These findings disclose an unreported relationship, underlining the specific ways in which these welfare configurations can negatively influence the health of individuals of higher SEPs - beyond ensuring a basic protection for all, that is be particularly relevant for individuals of lower SEPs.

Results must be understood considering their limitations. In the first place, a comparative analysis by welfare regimes can be contested itself, considering the limitations of any typology. Aggregating countries in different groups can contribute to neglecting important differences within different countries in the same cluster/region. For example, analysing the mediation coefficients concerning the Provided instrumental help by country we can find more cross-country variation in some regimes than others - none of the Scandinavian countries presented a relevant mediation through the provision of help; all Southern countries presented a positive and relevant mediation effect; whereas Bismarckian and Eastern regimes present wider cross-national variation (Table 4).

Theoretically, it makes sense to interpret the results considering regional differences in terms of welfare state regimes, especially in terms of defamilization/familiarization trends that clearly oppose northern from southern countries in Europe. Still the regions differ in other important aspects that cannot be controlled in this research design (cultural values, generalized living conditions, diet, income inequality or other). Also countries from the same welfare state regime can differ in terms of the national health systems or other social policy programmes with great implications on inequalities (e.g. Lundberg et al. 2010). 
A welfare regime typology was opted for to address the general features of states social policy and, therefore, some variation is expected among countries of the same group. Nevertheless it is important to better understand the implications of this and other dimensions of macro policy. Running the analysis by regimes separately does not allow identifying the factors/dimensions responsible for the regional variation. The implications of welfare state regimes and other macro-level constructs can be addressed in future research with multi-level regression analysis. Multi-level techniques were not suitable in this research due to the insufficient number of countries included in the fourth wave of the SHARE survey (there is a recommended minimum of 20 countries in multi-level analysis, Hox 1995), but the extension of the survey to more countries and the compatibility of the survey with the US Health and Retirement Study and the English Longitudinal Study of Ageing expand the possibilities to analyse the macro-contextual effects in health inequalities in future research. These possibilities can also ensure better conditions to assess the compliance of the regression models with causal assumptions concerning directionality, absence of error measures and the inclusion of all variables relevant to the relation.

Furthermore, it is important to acknowledge the dynamic character of these relations. The study relied on the distinction of regions with different

Table 4. Mediation coefficients' estimates for provided instrumental help by country.

\begin{tabular}{|c|c|c|c|c|c|c|c|}
\hline \multirow[b]{3}{*}{ Regime } & \multirow[b]{3}{*}{ Country } & \multirow{2}{*}{\multicolumn{2}{|c|}{$\begin{array}{c}\text { Path a } \\
\text { Factor SES - } \\
\text { Provided help }\end{array}$}} & \multirow{2}{*}{\multicolumn{2}{|c|}{$\begin{array}{c}\text { Path b } \\
\begin{array}{l}\text { Provided help - } \\
\text { Health }\end{array}\end{array}$}} & \multirow{2}{*}{\multicolumn{2}{|c|}{ Mediation }} \\
\hline & & & & & & & \\
\hline & & $B$ & SE & $B$ & SE & $B$ & SE \\
\hline \multirow[t]{2}{*}{ Northern } & Sweden & $.168^{* *}$ & .051 & -.059 & .042 & -.001 & .001 \\
\hline & Denmark & .088 & .047 & $.084^{*}$ & .036 & .001 & .001 \\
\hline \multirow[t]{5}{*}{ Bismarckian } & Austria & $.106^{* *}$ & .033 & $.118^{* * *}$ & .030 & $.002^{* *}$ & .001 \\
\hline & Germany & $.178^{* * *}$ & .056 & $.145^{* *}$ & .048 & $.004^{*}$ & .002 \\
\hline & The Netherlands & $.198^{* * *}$ & .042 & -.002 & .032 & .000 & .001 \\
\hline & France & $.148^{* * *}$ & .030 & .025 & .024 & .000 & .000 \\
\hline & Belgium & $.178^{* * *}$ & .030 & .014 & .026 & .000 & .001 \\
\hline \multirow{5}{*}{ Eastern } & Czech Republic & $.215^{* * *}$ & .028 & $.125^{* * *}$ & .024 & $.004^{* * *}$ & .001 \\
\hline & Poland & .090 & .062 & $.161^{* *}$ & .054 & .002 & .001 \\
\hline & Hungary & .061 & .042 & $.133^{* * *}$ & .038 & .001 & .001 \\
\hline & Slovenia & $.408^{* * *}$ & .052 & $.183^{* * *}$ & .043 & $.009 * * *$ & .002 \\
\hline & Estonia & $.150^{* * *}$ & .028 & .039 & .024 & .001 & .001 \\
\hline \multirow[t]{3}{*}{ Southern } & Spain & $.123^{* *}$ & .042 & $.255^{* * *}$ & .041 & $.004^{* *}$ & .001 \\
\hline & Italy & $.183^{* * *}$ & .038 & $.088^{* *}$ & .032 & $.002^{*}$ & .001 \\
\hline & Portugal & $.216^{* * *}$ & .052 & $.242^{* * *}$ & .051 & $.007^{* * *}$ & .002 \\
\hline
\end{tabular}

Notes: Regression coefficients $(B)$ and related standard error (SE). Mediation coefficients estimation based on coefficients presented in the comparable format in agreement with the proposal of MacKinnon and Dwyer (1993); statistical significance based on the Sobel test statistic.

${ }^{*} p<.05$.

$*^{* *} p<.01$.

${ }^{* * *} p<.001$. 
types of welfare state, which have effects in the characteristics and evolution of social policy, re-enforced by institutional inertia (Pierson 2000). Despite the stability of these features, welfare state regimes are not static. At a European level external pressures exist for welfare state reforms related to globalization, Europeanization, demographical evolutions and labour markets (Jaeger and Kvist 2003). The world financial crisis resulting from the US subprime crisis in 2008 and the consequential economic crisis have also resulted in important pressures for social policy change that appear to interrupt a convergence trend from the Southern countries towards the Bismarckian welfare regimes, and to contribute an increase of internal variation in Southern Europe (Petmesidou and Guillén 2014).

By separating the defining features of social networks, and studying the influence of those dimensions in the association between the SEP and health, links that attenuate and inflate health inequalities were identified. This research provided some interesting clues to further expand health inequality research. This approach can also promote the theoretical debate needed to clarify the processes through which the SEP influences the characteristics of the personal networks, how they influence health and health inequality, and how the socio-political context influences these relationships.

The findings concerning the differences between the regions, although not totally aligned with the initial predictions, are interpreted under the proposed framework and underlined the differential characteristics of welfare regimes. This provides some empirical support to the theoretical expectation concerning region variation in the mechanisms related to the association between SEP and health in later life. Further research is needed to provide grounds for the proposed interpretation, and the focus on specific pathways to health inequality appears to be an interesting analytical strategy.

\section{Disclosure statement}

No potential conflict of interest was reported by the author.

\section{Funding}

This paper uses data from SHARE Wave 4 (DOI: 10.6103/SHARE.w4.500). The SHARE data collection has been primarily funded by the European Commission through FP5 (QLK6-CT-2001-00360), FP6 (SHARE-I3: RII-CT-2006-062193, COMPARE: CIT5-CT-2005-028857, SHARELIFE: CIT4-CT-2006-028812) and FP7 
(SHARE-PREP: N²11909, SHARE-LEAP: N²27822, SHARE M4: N²61982). Additional funding from the German Ministry of Education and Research, the U.S. National Institute on Aging (U01_AG09740-13S2, P01_AG005842, P01_AG08291, P30_AG12815, R21_AG025169, Y1-AG-4553-01, IAG_BSR06-11, OGHA_04-064) and from various national funding sources is gratefully acknowledged (see www. share-project.org) and this work is also supported by Fundação para a Ciência e Tecnologia under doctoral degree grant [SFRH/BD/80052/2011].

\section{Notes on contributor}

Daniela Craveiro is a researcher in the Communication and Society Research Centre in University of Minho (CECS-UM). Her current research interests are on topics related to ageing society, health inequality and the welfare state.

\section{ORCID}

Daniela Craveiro (D) http://orcid.org/0000-0003-4365-2255

\section{References}

Abel, T. (2008) 'Cultural capital and social inequality in health', Journal of Epidemiology and Community Health 62(7): e13.

Abel, T., Fuhr, D. C., Bisegger, C. and Ackermann Rau, S. (2011) 'Money is not enough: Exploring the impact of social and cultural resources on youth health', Scandinavian Journal of Public Health 39(Suppl. 6): 57-61.

Anttonen, A. and Sipilä, J. (1996) 'European social care services: Is it possible to identify models?', Journal of European Social Policy 6: 87-100.

Arts, W. and Gelissen, J. (2002) 'Three worlds of welfare capitalism or more? A stateof-the-art report', Journal of European Social Policy 12(200205): 137-58.

Aspalter, C., Jinsoo, K. and Sojeung, P. (2009) 'Analysing the welfare state in Poland, the Czech Republic, Hungary and Slovenia: An ideal-typical perspective', Social Policy \& Administration 43(2): 170-85.

Avendano, M., Kawachi, I., Van Lenthe, F. V., Boshuizen, H. C., Mackenbach, J. P., Van Den Bos, G. M., Fay, M. E. and Berkman, L. F. (2006) 'Socioeconomic status and stroke incidence in the US elderly: The role of risk factors in the EPESE study', Stroke 37: 1368-73.

Bambra, C. (2011) 'Health inequalities and welfare state regimes: Theoretical insights on a public health "puzzle"', Journal of Epidemiology and Community Health 65(9): 740-5.

Beckfield, J. and Krieger, N. (2009) 'Epi + demos + cracy: Linking political systems and priorities to the magnitude of health inequities - evidence, gaps, and a research agenda', Epidemiologic Reviews 31: 152-77.

Berkman, L. F., Glass, T., Brissette, I. and Seeman, T. E. (2000) 'From social integration to health: Durkheim in the new millennium', Social Science and Medicine (1982) 51(6): 843-57. 
Bonoli, G. (1997) 'Classifying welfare states: A two-dimension approach', Journal of Social Policy, 26(3): 351-72.

Börsch-Supan, A., Brandt, M., Hunkler, C., Kneip, T., Korbmacher, J., Malter, F., Schaan, B., Stuck, S. and Zuber, S. (2013) 'Data resource profile: The survey of health, ageing and retirement in Europe (SHARE)', International Journal of Epidemiology 18: 1-10.

Bourdieu, P. (1984) Distinction: A Social Critique of the Judgement of Taste, London: Routledge.

Burstrom, B., Whitehead, M., Clayton, S., Fritzell, S., Vannoni, F. and Costa, G. (2010) 'Health inequalities between lone and couple mothers and policy under different welfare regimes - the example of Italy, Sweden and Britain', Social Science and Medicine (1982) 70(6): 912-20.

Chappell, N. L. and Funk, L. M. (2010) 'Social capital: Does it add to the health inequalities debate?', Social Indicators Research 99: 357-73.

Dahl, E. and Malmberg-Heimonen, I. (2010) 'Social inequality and health: The role of social capital', Sociology of Health and Illness 32(7): 1102-19.

Diderichsen, F., Evans, T. and Whitehead, M. (2001) 'The social basis of disparities in health', in T. Evans, M. Whitehead, F. Diderichsen, A. Bhuiya and M. Wirth (eds), Challenging Inequities in Health, New York: Oxford University Press, pp. 37-43.

DiMaggio, P. and Garip, F. (2012) 'Network effects and social inequality', Annual Review of Sociology 38(1): 93-118.

Eikemo, T. A. and Bambra, C. (2008) 'The welfare state: A glossary for public health', Journal of Epidemiology and Community Health 62(1): 3-6.

Eikemo, T. A., Bambra, C., Judge, K. and Ringdal, K. (2008) 'Welfare state regimes and differences in self-perceived health in Europe: A multilevel analysis', Social Science and Medicine (1982) 66(11): 2281-95.

Esping-Andersen, G. (1990) The Three Worlds of Welfare Capitalism, Oxford: Polity Press.

Esping-Andersen, G. (1999) Social Foundations of Postindustrial Economies, Oxford: Oxford University Press.

Ferlander, S. (2007) 'The importance of different forms of social capital for health', ActaSociologica 50(2): 115-28.

Ferrera, M. (1996) 'The "Southern model" of welfare in social Europe', Journal of European Social Policy 6(17): 17-37.

Fiori, K. L., Antonucci, T. C. and Cortina, K. S. (2006) 'Social network typologies and mental health among older adults', The Journals of Gerontology Series B: Psychological Sciences and Social Sciences 61(1): 25-32.

Freese, J. and Lutfey, K. (2011) 'Fundamental causality: Challenges of an animating concept for medical sociology', in B. A. Pescosolido, J. K. Martin, J. D. McLeod and A. Rogers (eds), Handbook of the Sociology of Health, Illness, and Healing. A Blueprint for the 21st Century, Chicago, IL: Springer New York, pp. 67-81.

García-Faroldi, L. (2015) 'Welfare states and social support: An international comparison', Social Indicators Research 121(3): 697-722.

Gelissen, J. P. T. M., van Oorschot, W. J. H. and Finsveen, E. (2012) 'How does the welfare state influence individuals' social capital? Eurobarometer evidence on individuals' access to informal help', European Societies 14(3): 416-40. 
Granovetter, M. S. (1973) 'The strength of weak ties', American Journal of Sociology 78 (6): $1360-80$.

Heritage, Z. (2009) 'Inequalities, social ties and health in France', Public health 123(1): e29-34.

Hox, J. (1995) Applied multilevel analysis, Amsterdam: TT Publikaties.

Hughner, R. S. and Kleine, S. S. (2004) 'Views of health in the lay sector: A compilation and review of how individuals think about health', Health (London) 8(4): 395-422.

Huurre, T., Eerola, M., Rahkonen, O. and Aro, H. (2007) 'Does social support affect the relationship between socioeconomic status and depression? A longitudinal study from adolescence to adulthood', Journal of Affective Disorders 100(100): 55-64.

Jaeger, M. and Kvist, J. (2003) 'Pressures on state welfare in post-industrial societies: Is more or less better?', Social Policy and Administration 37(6): 555-72.

Kääriäinen, J. and Lehtonen, H. (2006) 'The variety of social capital in welfare state regimes - a comparative study of 21 countries', European Societies 8(1): 27-57.

Kalmijn, M. and Saraceno, C. (2008) 'A comparative perspective on intergenerational support', European Societies 10(3): 479-508.

Koster, A., Bosma, H., Kempen, G. I. J. M., Penninx, B. W. J. H., Beekman, A. T. F., Deeg, D. J. H. and van Eijk, J. T. M. (2006) 'Socioeconomic differences in incident depression in older adults: The role of psychosocial factors, physical health status, and behavioural factors', Journal of Psychosomatic Research 61(5): 619-27.

Leitner, S. (2003) 'Varieties of familialism: The caring function of the family in comparative perspective', European Societies 5(4): 353-75.

Litwin, H. (1998) 'Social network type and health status in a national sample of elderly Israelis', Social Science and Medicine (1982) 46(4-5): 599-609.

Litwin, H. (2009) 'Social networks and well-being: A comparison of older people in Mediterranean and non-Mediterranean countries', The Journals of Gerontology Series B: Psychological Sciences and Social Sciences 65(5): 599-608.

Litwin, H. and Stoeckel, K. J. (2014) 'Confidant network types and well-being among older Europeans', The Gerontologist 54: 762-72.

Liu, X., Hermalin, a I. and Chuang, Y. L. (1998) 'The effect of education on mortality among older Taiwanese and its pathways', The Journals of Gerontology Series B: Psychological Sciences and Social Sciences 53(2): S71-82.

Lundberg, O., Fritzell, J., ÅbergYngwe, M. and Kölegård, M. L. (2010) 'The potential power of social policy programmes: Income redistribution, economic resources and health', International Journal of Social Welfare 19: S2-13.

Mackenbach, J. P. (2012) 'The persistence of health inequalities in modern welfare states: The explanation of a paradox', Social Science and Medicine (1982) 75(4): 761-9.

MacKinnon, D. P. and Dwyer, J. H. (1993) 'Estimating mediated effects in prevention studies', Evaluation Review, 17: 144-58.

MacKinnon, D. P., Lockwood, C. M., Hoffman, J. M., West, S. G. and Sheets, V. (2002) 'A comparison of methods to test mediation and other intervening variable effects', Psychological Methods 7: 83-104.

Olasfsdottir, S. and Beckfield, J. (2010) 'Health and the social rights of citizenship: Integrating welfare-state theory and medical sociology', in B. A. Pescosolido, J. 
K. Martin, J. D. McLeod and A. Rogers (eds), Handbook of the Sociology of Health, Illness, and Healing. A Blueprint for the 21st Century, Chicago, IL: Springer New York, pp. 101-16.

van Oorschot, W. and Finsveen, E. (2009) 'The welfare state and social capital inequality', European Societies 11(2): 189-210.

Petmesidou, M. and Guillén, A. M. (2014) 'Can the welfare state as we know it survive? A view from the crisis-ridden south European periphery', South European Society and Politics 19(3): 295-307.

Phelan, J. C., Link, B. G. and Tehranifar, P. (2010) 'Social conditions as fundamental causes of health inequalities: Theory, evidence, and policy implications', Journal of Health and Social Behavior 51(Suppl. 1): S28-40.

Pierson, P. (2000) 'Three worlds of welfare state research', Comparative Political Studies, 33(6): 791-821.

Pirani, E. and Salvini, S. (2011) 'Socioeconomic inequalities and self-rated health: A multilevel study of Italian elderly', Population Research and Policy Review 31(1): 97-117.

Quesnel-Valleé, A. (2007) 'Self-rated health: Caught in the crossfire of the quest for “true” health?', International Journal of Epidemiology 36: 1161-64.

Requena, F. (2010) 'Welfare systems, support networks and subjective well-being among retired persons', Social Indicators Research 99(3): 511-29.

Scheepers, P., Grotenhuis, M. T. and Gelissen, J. (2002) 'Welfare states and dimensions of social capital: Cross-national comparisons of social contacts in European countries', European Societies 4(2): 185-207.

Smith, K. P. and Christakis, N. A. (2008) 'Social networks and health', Annual Review of Sociology, 34: 405-29.

Sobel, M. E. (1982) 'Asymptotic confidence intervals for indirect effects in structural equations models', in S. Leinhart (ed.), Sociological Methodology, San Francisco, CA: Jossey-Bass, pp. 290-312.

Thoits, P. (2011) 'Mechanisms linking social ties and support to physical and mental health', Journal of Health and Social Behavior 52: 145-61.

Uphoff, E. P., Pickett, K. E., Cabieses, B., Small, N. and Wright, J. (2013) 'A systematic review of the relationships between social capital and socioeconomic inequalities in health: A contribution to understanding the psychosocial pathway of health inequalities', International Journal for Equity in Health 19(1): 12-54.

Waite, L. and Das, A. (2010) 'Families, social life, and well-being at older ages', Demography 47(Suppl. 1): S87-109.

Whitehead, M. and Dahlgren, G. (2007) Concepts and Principles for Tackling Social Inequities in Health: Levelling Up Part 1, Copenhagen: WHO. 